\title{
Measurement properties and performance of an eight-minute submaximal treadmill test in patients with juvenile idiopathic arthritis: a controlled study
}

Kristine Risum ${ }^{1,2^{*}}$ (D) Elisabeth Edvardsen ${ }^{3,4}$, Anne M. Selvaag ${ }^{5}$, Hanne Dagfinrud ${ }^{2,6}$ and Helga Sanner $5,7,8$

\begin{abstract}
Background: Poor cardiorespiratory fitness is previously reported in patients with juvenile idiopathic arthritis (JIA) measured both by maximal and submaximal exercise tests, but a submaximal exercise test with acceptable measurement properties is currently lacking for both clinical and research purposes in this patient population. The objectives of this study were to evaluate the measurement properties and performance of a submaximal treadmill test in patients with $\mathrm{JIA}$, and to compare the results with those obtained in controls.
\end{abstract}

Methods: Fifty-nine patients (50 girls), aged 10-16 years, with oligo- $(n=30)$ and polyarticular $(n=29)$ JIA, and 59 age- and sex-matched controls performed an eight-minute submaximal treadmill test for estimating peak oxygen uptake $\left(\mathrm{VO}_{2 \text { peak }}\right)$ followed by a maximal treadmill test measuring $\mathrm{VO}_{\text {2peak }}$ directly. During the submaximal treadmill test, the study participants walked with no inclination at a speed between $3.2-7.2 \mathrm{~km} / \mathrm{h}$ for four minutes, and then continued to walk at the same speed for four minutes with five $\%$ inclination. $\mathrm{VO}_{2 \text { peak }}$ was directly measured during a continuous graded exercise test on treadmill until exhaustion. Thirty-seven patients participated in the evaluation of the reliability. Criterion validity and reliability were evaluated with interclass correlation coefficient (ICC); measurement errors by Bland-Altman plot, standard error of measurement and smallest detectable change.

Results: In patients with JIA, the ICC $(95 \%$ Cl) for criterion validity was acceptable at group level $0.71(0.51,0.82)$, but not at individual level. The test-retest reliability and inter-rater reliability were acceptable at individual $(0.84(0.71,0.91)$ and $0.92(0.83,0.96)$, respectively) and group levels $(0.91(0.83,0.96)$ and $0.96(0.91,0.98)$, respectively). The measurement errors (for test-retest reliability/inter-rater reliability) were large. Bland-Altman plots showed no systematic differences, but a large variability for both the validity and reliability. The performance of and estimated $\mathrm{VO}_{2 \text { peak }}$ from the submaximal test were not associated with disease variables and were comparable between patients and controls.

Conclusion: The submaximal treadmill test is valid for use in patients with JIA on group level, but not on individual level. The reliability is acceptable. Due to large measurement errors, the submaximal treadmill test is not optimal for use in daily clinical practice to estimate $\mathrm{VO}_{2 \text { peak }}$ in individual patients.

Keywords: Juvenile idiopathic arthritis, Cardiorespiratory fitness, Exercise testing, Validity, Reliability, Measurement properties

\footnotetext{
* Correspondence: krisum@ous-hf.no

${ }^{1}$ Division of Orthopaedic Surgery, Section for Orthopaedic Rehabilitation,

Oslo University Hospital, Rikshospitalet, Postboks 4950 Nydalen, 0424 Oslo,

Norway

${ }^{2}$ Department of Health Sciences, Institute of Health and Society, Oslo, Faculty

of Medicine, University of Oslo, Oslo, Norway

Full list of author information is available at the end of the article
}

(c) The Author(s). 2019 Open Access This article is distributed under the terms of the Creative Commons Attribution 4.0 International License (http://creativecommons.org/licenses/by/4.0/), which permits unrestricted use, distribution, and

reproduction in any medium, provided you give appropriate credit to the original author(s) and the source, provide a link to the Creative Commons license, and indicate if changes were made. The Creative Commons Public Domain Dedication waiver (http://creativecommons.org/publicdomain/zero/1.0/) applies to the data made available in this article, unless otherwise stated. 


\section{Background}

Juvenile idiopathic arthritis (JIA) can affect physical function and cardiorespiratory fitness (CRF). CRF is important for general health, and high CRF has been shown to decrease cardiovascular disease in general pediatric and adult populations [1-3]. Previous studies have shown that patients with JIA have poor CRF measured with both maximal and submaximal exercise tests [4-6]. Contrary to these results, we have recently reported that patients with oligo- and polyarticular JIA diagnosed in the era of biologics have comparable levels of CRF as age- and sex-matched controls from the general population, measured directly as peak oxygen uptake $\left(\mathrm{VO}_{2 \text { peak }}\right)$ [7]. We believe our positive results may be explained by advances in the multidisciplinary management of JIA in the era of biologics, as well as differences in study populations. Importantly, $20-30 \%$ of both our patients with JIA and controls had poor CRF.

The gold standard method to measure CRF is through a cardiopulmonary exercise test (CPET) with direct measurement of $\mathrm{VO}_{2 \text { peak }}$, using a treadmill or bicycle to maximal exhaustion [8]. However, a CPET is time consuming, requires advanced and expensive equipment in a laboratory setting and extensive experience to encourage individuals to achieve maximal effort. Furthermore, performing a maximal exercise test may be uncomfortable and unpleasant for patients.

In contrast, indirect submaximal tests do not require the individuals to exercise to exhaustion, are easier to perform, require less advanced equipment, and are therefore frequently used in research and clinical practice to measure CRF [9]. The disadvantage of submaximal tests is less precise measurements of CRF compared to direct measurement of $\mathrm{VO}_{2 \text { peak. }}$. Submaximal tests are usually developed to provide estimation of $\mathrm{VO}_{2 \text { peak }}$ or to assess the distance covered in a given period of time or the time taken to cover a given distance. The most commonly used submaximal test in chronic pediatric conditions is probably the 6-min walk test $(6 \mathrm{MWT})$, even if the measurement properties vary largely among chronic pediatric conditions [10]. In JIA, the 6MWT has been suggested as a possible field test to measure walking ability, but is shown to be a poor predictor of $\mathrm{VO}_{2 \text { peak }}[6,11]$. To the best of our knowledge, no submaximal walking tests aiming to estimate $\mathrm{VO}_{2 \text { peak }}$ have been validated in pediatric populations.

An eight-minute submaximal treadmill test has been developed to estimate $\mathrm{VO}_{2 \text { peak }}$ in healthy adults [12], and is proven valid for women with rheumatic diseases [13], who may experience similar symptoms as patients with pediatric rheumatic diseases. However, in healthy adults the test seems to either under- or overestimate $\mathrm{VO}_{2 \text { peak }}$ depending on the chosen intensity [14]. The validity of this test is unknown for patients with JIA and healthy children. Also, knowledge about the reliability of the test is essential for both clinical practice and research purposes. Knowledge about how the performance of the test relate to disease variables is also warranted.

The objectives of the study were to evaluate the criterion validity and reliability of the eight-minute submaximal treadmill test in patients with JIA; also to investigate if the performance of the submaximal treadmill test is influenced by disease characteristics or differ from controls.

\section{Methods}

\section{Study participants}

This study is part of a larger study examining physical activity and physical fitness in patients with JIA diagnosed in the era of biologics $[7,15]$. From January to August 2015, consecutive patients aged $10-16$ years with polyarticular (extended oligoarthritis and polyarticular RF +/-) and oligoarticular JIA according to the ILAR criteria [16] with a planned routine follow-up at Oslo University Hospital (OUS) were recruited (JIA validity sample). We included these JIA categories to be able to compare homogenous JIA subgroups in the physical fitness and physical activity studies. Other inclusion criteria were disease duration $>6$ months and a home address in the geographical area served by the South-Eastern Norway Regional Health Authority. Exclusion criteria for patients were comorbidities associated with, or potentially associated with, impaired cardiopulmonary fitness (e.g heart- or lung disease, severe orthopedic conditions or recent surgery) or inability to walk. In addition, age- and sex-matched controls from the general population (living in or nearby Oslo) were randomly selected from the National Registry, and were included from November 2015 to March 2016 (controls validity sample). Exclusion criteria for the controls were inflammatory rheumatic or autoimmune disease, severe heart or lung disease, or other diseases involving mobility problems.

To evaluate the reliability of the submaximal treadmill test, patients living in or nearby Oslo and patients with a planned follow-up at OUS within 4 weeks, also performed the submaximal treadmill test 1-4 weeks after the initial test (JIA reliability sample). In general, a sample size of 50 participants is considered to be adequate when assessing reliability and validity [17].

Our study was conducted in compliance with the Helsinki Declaration and all participants provided written informed consent (the children themselves if aged $\geq 16$ years and the parents/guardians of children aged < 16 years together with the children's assent). The study was approved by the Norwegian South East Regional Ethics Committee for Medical Research (2014/188).

Assessment of demographic and disease-related variables Height and bodyweight were measured to the nearest $0.1 \mathrm{~cm}$ using a stadiometer and $0.1 \mathrm{~kg}$ on a digital scale, respectively, with participants wearing light clothes and 
no shoes. Body mass index (BMI) was calculated. Waist circumference was measured at the midpoint between the bony markers of the ribs and the superior iliac crest in a standing position at the end of expiration with a measuring tape at the height of umbilicus to the nearest $0.1 \mathrm{~cm}$. Current pain, pain and fatigue during the previous week were assessed by numeric rating scale (NRS) $0-10$, where $0=$ no pain/fatigue and $10=$ worst possible pain/fatigue [18]. In patients, disease activity was assessed by the Juvenile Arthritis Disease Activity Score 71 (JADAS 71) [19]. The Wallace criteria were used to determine if patients had active disease or clinical inactive disease [20]. The Childhood Health Assessment Questionnaire (CHAQ) was used to measure functional disability $[21,22]$. The patients completed the CHAQ themselves, with parental assistance if needed.

\section{Submaximal treadmill test}

We used the submaximal treadmill test developed by Ebbeling et al. [12] to estimate $\mathrm{VO}_{2 \text { peak }}$ (Technogym, Rimini, Italy). During the first four minutes of the test, the participant walked with no inclination at a speed between $3.2 \mathrm{~km} / \mathrm{h}(2.0 \mathrm{mph})$ and $7.2 \mathrm{~km} / \mathrm{h}(4.5 \mathrm{mph})$ corresponding to a heart rate (HR) between 50 to $70 \%$ of age-predicted peak $\mathrm{HR}\left(\mathrm{HR}_{\text {peak }}\right)$ of 220-age [23]. If possible, we aimed for a HR close to $70 \%$ of the predicted $H R_{\text {peak }}$ and the speed was gradually increased until this intensity was reached. If a HR close to $70 \%$ of predicted $\mathrm{HR}_{\text {peak }}$ was not reached at the speed of $7.2 \mathrm{~km} / \mathrm{h}(4.5$ $\mathrm{mph}$ ), the participant's HR at this intensity was recorded. After four minutes, the treadmill elevation was then gradually increased (within 15-20s) to five \% for the next four minutes. HR was measured at the end of each stage with a heart rate monitor (Polar Sports Watch, Kempele, Finland). Participants rated their perceived exertion (RPE) using the Borg Scale ${ }_{6-20}$ [24] at three and eight minutes. The Borg Scale ${ }_{6-20}$ is a subjective measure of a person's exertion during exercise, ranging from 6 to 20 , where $6=$ no exertion at all and $20=$ maximal exertion. The HR and walking speed achieved after eight minutes of walking were then recorded for entry into the previously developed equation to estimate $\mathrm{VO}_{2 \text { peak }}$ $\left(\mathrm{mL} \cdot \mathrm{kg}^{-1} \cdot \mathrm{min}^{-1}\right)$ based on the following equation [12]:

$$
\begin{aligned}
15.1 & +(21.8 \times \text { speed }[\mathrm{mph}]) \\
& -(0.327 \times \mathrm{HR}[\mathrm{bpm}]) \\
& -(0.26 \times \text { speed }[\mathrm{mph}] \times \text { age }[\mathrm{yrs}]) \\
& +(0.00504 \times \mathrm{HR} \times \text { age }) \\
& +(5.98 \times \text { sex }[\text { female }=0 ; \text { male }=1])
\end{aligned}
$$

We also recorded the total walking distance $(\mathrm{m})$ the participants walked during the submaximal treadmill test. Evaluation of the submaximal treadmill performance included HR and RPE at three and eight minutes, speed and walking distance.

\section{Maximal treadmill test}

CRF was directly measured as $\mathrm{VO}_{2 \text { peak }}\left(\mathrm{mL} \cdot \mathrm{kg}^{-1} \cdot \mathrm{min}^{-1}\right)$ during a maximal treadmill test (Woodway, Würzburg, Germany). The test protocol and procedure are described previously [7]. Briefly, gas exchange and ventilator variables were measured continuously breath-by-breath as the participants breathed into a two-way breathing mask (2700 series; Hans Rudolph, Inc., Shawnee KS, USA). The gas exchange variables were reported as $30 \mathrm{~s}$ averages using a gas analyzer (Vmax, SensorMedics, Yorba Linda, CA, USA). The highest achieved oxygen uptake averaged over a 30 -s period was defined as $\mathrm{VO}_{2 \text { peak. }}$. The highest respiratory exchange ratio (RER) measured before or corresponding to the highest minute ventilation was reported. RER is the ratio between the $\mathrm{VCO}_{2}$ and $\mathrm{VO}_{2}$, and increases with exercise intensity. The HR was recorded every minute using Polar Sports Watch (Kempele, Finland) and the $\mathrm{HR}_{\text {peak }}$ was reported. The RPE was rated by Borg Scale ${ }_{6-20}$ [24], and the participants also gave reason for terminating the test. The test was terminated when the participant was unable to continue, even with encouragement.

\section{Standardization of the conditions for treadmill testing}

Both validity samples (JIA and controls) performed the submaximal treadmill test prior to the maximal treadmill test on the same day, separated by approximately 30-60 min rest between each test. Both validity samples performed the submaximal treadmill test at $9.30 \mathrm{AM}$ at the earliest, thereby most likely avoiding issues with morning stiffness. If unfamiliar with treadmill walking, participants practiced until they felt comfortable to start the submaximal treadmill test. The JIA reliability sample performed the submaximal treadmill test twice on the second test day after school, separated by approximately 15 min rest between each test. The same physiotherapist (KR) conducted all maximal and submaximal treadmill tests used to evaluate criterion validity and test-retest reliability. To test inter-rater reliability, KR and a second physiotherapist, both with more than 13 years of clinical experience in pediatric rheumatology, conducted the submaximal treadmill tests on the second test session.

\section{Statistical analyses}

A power analysis was performed to estimate the required sample size for reliability testing of the submaximal treadmill test to achieve an ICC of 0.85 with a $95 \%$ confidence interval $(\mathrm{CI})$ and an interval width of $0.2(0.75$ and 0.95$)$. This calculation resulted in a sample size of 31 participants.

Descriptive data are presented as percentages, means (SD) and medians (25th-75th percentile) as appropriate. 
The COnsensus-based Standards for the selection of health Measurement INstruments (COSMIN) panel recommendations for measurement properties were followed for the evaluation of validity and reliability [17]. The observed $\mathrm{VO}_{2 \text { peak }}$ from the maximal treadmill test was considered the criterion measurement.

Paired $t$ tests were used to examine potential differences between the observed and estimated $\mathrm{VO}_{2 \text { peak }}$ and between the estimated $\mathrm{VO}_{2 \text { peak }}$ values from the three submaximal treadmill tests. Criterion validity and reliability were evaluated with two-ways mixed interclass correlation coefficient $_{\text {agreement }}$ (ICC). ICC $>0.70$ was considered acceptable [17]. Limits of agreement (LoA) (Bland and Altman method), standard error of measurement (SEM agreement $_{\text {) }}$ ) and smallest detectable change $\left(\mathrm{SDC}_{95}\right)$ were calculated to evaluate the measurement errors of the submaximal treadmill test. The SEM agreement represents the standard deviation of repeated measures in one patient, and was calculated with values from a two-way ANOVA. The SDC represents the minimal change that a patient must show on the scale to ensure that the observed change is real and larger than the measurement error. The SDC was calculated as $1.96 \times \sqrt{ } 2 \times \mathrm{SEM}_{\text {agreement }}$ to obtain $95 \% \mathrm{CI}$. The $\mathrm{SDC}$ values at the group level (SDC $\mathrm{Sroup}_{\text {) }}$ ) were calculated as $1.96 \times \sqrt{ } 2 \times \mathrm{SEM}_{\text {agreement }} / \sqrt{\mathrm{n}}$.

The Bland and Altman method was used to assess whether there was any systematic disagreement between the submaximal and maximal treadmill test and between the submaximal treadmill tests for both test-retest reliability and inter-rater reliability through a Bland and Altman plot. LoA were calculated as the mean difference in scores $\pm(1.96 \times \mathrm{SD}$ of the difference).

Differences between patients and controls were tested with independent sample $t$ tests and correlations with Spearman's rho correlation coefficients.

All statistical analyses were conducted using SPSS version 23 for windows package (SPSS, Chicago, IL, USA) with the level of significance set at $P<0.05$.

\section{Results}

\section{Characteristics of patients and controls}

The flow of study participants is shown in Fig. 1. Demographic characteristics of the validity samples of patients and controls and the JIA reliability sample are displayed in Table 1. A total of 59 patients (50 girls) with oligo- $(n=$ $30)$ and polyarticular $(n=29)$ JIA and 59 matched controls with complete data on the maximal and submaximal treadmill tests were included in the analyses to evaluate the criterion validity. Mean age (SD) was 13.6 (2.2) years in patients and 13.5 (2.6) years in controls. In patients, disease activity was moderate with a median (25th -75 th percentile) JADAS of $3.2(1.1-4.8)$, and $42 \%$ used biologic DMARDs (Table 1). Twenty-nine patients reported morning stiffness, but morning stiffness lasting 60-120 min or >
120 min was only reported by four patients and one patient, respectively. There was no clinical indication of cardiopulmonary side effects from synthetic or biologic DMARDs considered to be of importance for CRF. The JIA reliability sample included 37 patients (30 girls).

\section{Criterion validity in patients and controls}

All participants were able to perform both the submaximal and maximal treadmill tests according to the test protocols for each test. None of the study participants experienced any adverse events during the treadmill testing. The results from the maximal and submaximal treadmill tests are shown in Table 2. For the maximal treadmill test, the mean $\mathrm{HR}_{\text {peak }}$, RER and RPE (Borg scale $_{6-20}$ ) indicate that the participants exercised at their maximal capacity. This is underlined by the fact that all participants reported exhaustion as the reason for terminating the maximal treadmill test. As previously published [7], there were no significant differences between patients and controls for any variables from the maximal treadmill test. For the submaximal treadmill test, the HR and RPE reported during and immediately after the test indicate that both patients and controls exercised at submaximal intensity. In total, 44 (75\%) patients and 41 (70\%) controls reached the target HR of $70 \%$ of predicted $\mathrm{HR}_{\text {peak }}$ during the submaximal treadmill test. The remaining patients and controls reached a HR between 60 and $70 \%$ of predicted $\mathrm{HR}_{\text {peak }}$.

In patients, no significant difference was found between the observed and estimated $\mathrm{VO}_{2 \text { peak }}\left(\mathrm{mL} \cdot \mathrm{kg}^{-}\right.$ $\left.{ }^{1} \cdot \mathrm{min}^{-1}\right)$; $44.8(8.8)$ vs 43.2 (10.3), respectively, $P=0.18$. The ICC $(95 \% \mathrm{CI})$ at group level was acceptable; 0.71 $(0.51,0.82)$, while the single ICC value at individual level between the observed and estimated $\mathrm{VO}_{2 \text { peak }}$ was not acceptable; $0.55(0.34,0.70)$. LoA showed large variation between the observed and estimated $\mathrm{VO}_{2 \text { peak }}(-16.4$ to $19.4 \mathrm{~mL} \cdot \mathrm{kg}^{-1} \cdot \mathrm{min}^{-1}$ ), with no systematic bias (Fig. 2a).

In controls, no significant difference was found between the observed and estimated $\mathrm{VO}_{2 \text { peak }}\left(\mathrm{mL} \cdot \mathrm{kg}^{-1} \cdot \mathrm{min}^{-1}\right)$; 46.53 (8.47) vs 44.60 (7.92), respectively, $P=0.12$. Neither the ICC $(95 \% \mathrm{CI})$ value at group level nor individual level were acceptable; $0.52(0.21,0.71)$ and $0.35(0.11,0.56)$, respectively. LoA showed large variation between the observed and estimated $\mathrm{VO}_{2 \text { peak }}\left(-16.3\right.$ to $20.1 \mathrm{~mL} \cdot \mathrm{kg}^{-}$ ${ }^{1} \cdot \mathrm{min}^{-1}$ ), with no systematic bias (Fig. $2 \mathrm{~b}$ ).

\section{Reliability in patients}

Paired $t$ tests showed no significant differences in estimated $\mathrm{VO}_{\text {2peak }}\left(\mathrm{mL} \cdot \mathrm{kg}^{-1} \cdot \mathrm{min}^{-1}\right)$ when comparing the results from the submaximal treadmill tests (Table 3). Both the test-retest reliability and inter-rater reliability were acceptable at group level (ICC (95\% CI) $0.91(0.83,0.96)$ and 0.96 (0.91, 0.98), respectively) and at individual level $(0.84(0.71,0.91)$ and 0.92 $(0.83,0.96)$, respectively). The measurement errors were 




large for both test-retest reliability and inter-rater reliability (Table 3). The $\mathrm{SDC}_{95}$ values indicate that a change greater than $11.4 \mathrm{~mL} \cdot \mathrm{kg}^{-1} \cdot \mathrm{min}^{-1}$ for the test-retest reliability and $8.6 \mathrm{~mL} \cdot \mathrm{kg}^{-1} \cdot \mathrm{min}^{-1}$ for the inter-rater reliability would be required to be $95 \%$ certain that a change would not be the result of measurement error, but of a real change. The $\mathrm{SDC}_{95 \text { group }}$ (at group level) values indicated that a change of greater than $1.5 \mathrm{~mL} \cdot \mathrm{kg}^{-1} \cdot \mathrm{min}^{-1}$ for the test-retest reliability and $1.1 \mathrm{~mL} \cdot \mathrm{kg}^{-1} \cdot \mathrm{min}^{-1}$ for the inter-rater reliability, would be required to be $95 \%$ certain that a change would not be the result of measurement error, but of a real change.

The Bland and Altman plots showed no systematic differences, but the LoA confirmed the large variability of agreement in estimated $\mathrm{VO}_{2 \text { peak }}$ for both test-retest reliability and inter-rater reliability (Fig. 2c and d).

\section{Estimated $\mathrm{VO}_{2 \text { peak }}$ and performance of the submaximal treadmill test between patients and controls, and correlation with disease variables}

Estimated $\mathrm{VO}_{2 \text { peak }}\left(\mathrm{mL} \cdot \mathrm{kg}^{-1} \cdot \mathrm{min}^{-1}\right)$ and performance of the submaximal treadmill test did not differ significantly between patients and controls, all P's $>0.15$ (Table 2). Estimated $\mathrm{VO}_{2 \text { peak }}\left(\mathrm{mL} \cdot \mathrm{kg}^{-1} \cdot \mathrm{min}^{-1}\right)$ and performance of the submaximal treadmill test were also comparable between patients with persistent oligo- and polyarticular JIA and between patients with active and clinical inactive disease (data not shown). In patients, there were no correlations between any disease variables and estimated $\mathrm{VO}_{2 \text { peak }}$ or walking distance (Table 4).

\section{Discussion}

This is the first study to examine criterion validity and reliability of the eight-minute submaximal treadmill test aiming to estimate $\mathrm{VO}_{\text {2peak }}$ in patients with JIA. The results showed acceptable measurement properties on group level for both validity and reliability. The reliability was acceptable measured by ICC, but the measurement errors were large. On individual level, the validity was not acceptable, with large limits of agreement, and with no systematic bias. In controls, the validity of the submaximal treadmill test was not acceptable neither on group nor individual level. Patients with JIA and 
Table 1 Characteristics of patients with JIA and controls

\begin{tabular}{|c|c|c|c|}
\hline & $\begin{array}{l}\text { Patients with JIA } \\
\text { validity sample }(n=59)\end{array}$ & $\begin{array}{l}\text { Patients with JIA } \\
\text { reliability sample }(n=37)\end{array}$ & $\begin{array}{l}\text { Controls validity } \\
\text { sample }(n=59)\end{array}$ \\
\hline Age (yrs) & $13.6(2.2)$ & $13.6(2.1)$ & $13.5(2.6)$ \\
\hline Female sex, n (\%) & $50(85)$ & $30(81)$ & $50(85)$ \\
\hline Height $(\mathrm{cm})$ & $157.6(12.5)$ & $158.5(13.0)$ & $160.8(12.3)$ \\
\hline Weight (kg) & $48.3(11.8)$ & $49.5(12.7)$ & $53.1(15.2)$ \\
\hline BMI $\left(\mathrm{kg} / \mathrm{m}^{2}\right)$ & $19.2(3.0)$ & $19.4(3.3)$ & $20.1(3.5)$ \\
\hline Waist circumference (cm) & $70.5(9.8)$ & $70.2(8.9)$ & $69.3(9.2)$ \\
\hline Pubertal status (pre-, mid-, and postpubertal \%) & $24 / 61 / 15$ & $22 / 65 / 13$ & $17 / 68 / 15$ \\
\hline NRS current pain (0-10), n (\%) score $>0$ & $23(38)$ & $16(43)$ & $18(30)$ \\
\hline NRS pain previous week (0-10) & $1.0(0.0-3.0)$ & $1.0(1.0-3.5)$ & $1.0(0.0-3.0)$ \\
\hline NRS fatigue previous week (0-10) & $3(2.0-6.0)$ & $3.0(2.0-6.0)$ & $3.0(1.0-5.0)$ \\
\hline Oligo/poly, n (\%) & $30(51) / 29(49)$ & $18(49) / 19(51)$ & NA \\
\hline Disease duration (yrs) & $7.5(3.8)$ & $7.5(3.9)$ & NA \\
\hline JADAS 71 (0-101) & $3.2(1.1-4.8)$ & $3.0(1.0-4.7)$ & NA \\
\hline CHAQ score (0-3) & $0.0(0.0-0.3)$ & $0.1(0.0-0.4)$ & NA \\
\hline Off medication, n (\%) & $12(20)$ & $9(24)$ & NA \\
\hline Synthetic DMARDs, n (\%) & $39(66)$ & $24(65)$ & NA \\
\hline Biologic DMARDs, n (\%) & $25(42)$ & $15(41)$ & NA \\
\hline Active disease, n (\%) & $20(34)$ & $12(32)$ & NA \\
\hline Inactive disease, n (\%) & $39(66)$ & $25(68)$ & NA \\
\hline
\end{tabular}

Numbers are mean (SD) or median (25th - 75th percentile) unless otherwise indicated. JIA juvenile idiopathic arthritis, BMI body mass index, NRS numeric rating scale, JADAS juvenile arthritis disease activity score, CHAQ childhood health assessment questionnaire, DMARDs disease modifying anti-rheumatic drugs, NA not applicable

Table 2 Data characteristics of the submaximal and maximal tests used for the evaluation of criterion validity in patients with JIA and controls

\begin{tabular}{|c|c|c|c|}
\hline & & $\begin{array}{l}\text { Patients with JIA } \\
(n=59)\end{array}$ & $\begin{array}{l}\text { Controls } \\
(n=59)\end{array}$ \\
\hline \multicolumn{4}{|c|}{ Maximal test } \\
\hline \multicolumn{2}{|c|}{$V O_{\text {2peak }}\left(\mathrm{mL} \cdot \mathrm{kg}^{-1} \cdot \mathrm{min}^{-1}\right)$} & $45.1(8.5)$ & $46.5(8.5)$ \\
\hline \multicolumn{2}{|c|}{ Running distance (m) } & 909 (236) & $968(190)$ \\
\hline \multicolumn{2}{|c|}{ Peak HR (beats/min) } & $196(9)$ & $197(7)$ \\
\hline \multicolumn{2}{|c|}{ Borg $6-20$} & $18.9(1.9)$ & $18.5(1.0)$ \\
\hline \multicolumn{2}{|c|}{ Respiratory exchange ratio } & $1.27(0.12)$ & $1.23(0.10)$ \\
\hline \multicolumn{2}{|c|}{ Test time (sec) } & $527(99)$ & $554(76)$ \\
\hline \multicolumn{2}{|c|}{ Speed $(\mathrm{km} / \mathrm{h})$} & $8.3(0.9)$ & $8.5(0.7)$ \\
\hline \multicolumn{2}{|c|}{ Gradient (\%) } & $11.5(1.7)$ & $11.8(1.4)$ \\
\hline \multicolumn{4}{|c|}{ Submaximal test } \\
\hline \multicolumn{2}{|c|}{$\begin{array}{l}\text { Estimated } \mathrm{VO}_{2 \text { peak }} \\
\left(\mathrm{mL} \cdot \mathrm{kg}^{-1} \cdot \mathrm{min}^{-1}\right)\end{array}$} & $43.6(9.9)$ & $44.6(7.9)$ \\
\hline \multicolumn{2}{|c|}{ Walking distance (m) } & $751(91)$ & $739(67)$ \\
\hline \multicolumn{2}{|c|}{ Speed $(\mathrm{km} / \mathrm{h})$} & $6.2(0.8)$ & $6.2(0.6)$ \\
\hline \multirow[t]{2}{*}{$3 \mathrm{~min}$} & HR (beats/min) & $134(9)$ & $132(9)$ \\
\hline & Borg 6-20 & $9.6(2.0)$ & $9.4(2.2)$ \\
\hline \multirow[t]{2}{*}{$8 \min$} & HR (beats/min) & $163(14)$ & $159(14)$ \\
\hline & Borg $6-20$ & $13.0(2.2)$ & $12.4(2.2)$ \\
\hline
\end{tabular}

Numbers are mean (SD). JIA juvenile idiopathic arthritis, $H R$ heart rate, $\mathrm{VO}_{\text {2peak }}$ peak oxygen uptake controls had similar estimated $\mathrm{VO}_{2 \text { peak }}$ and submaximal treadmill test performance, and we found no associations with disease variables.

Compared to our results, studies on healthy adults [14] and women with rheumatic diseases [13] showed better validity. However, these studies applied different statistical methods than ours, making comparisons challenging. We applied ICC and Bland and Altman plots to evaluate criterion validity and reliability, statistical analyses methods recommended for these purposes by the COSMIN panel [17].

In the original study of the submaximal treadmill test, Ebbeling et al. [12] reported that there were no significant differences between the estimated and observed $\mathrm{VO}_{2 \text { peak }}$ values in healthy adults, suggesting that the test has good predictive validity. We found similar results in both patients with JIA and controls when comparing estimated and observed $\mathrm{VO}_{2 \text { peak }}$ mean values using paired $\mathrm{t}$ tests. The ICC value for evaluation of criterion validity at group level was acceptable in patients, but not in controls. However, our agreement analyses in both patients and controls showed large variation between the observed and estimated $\mathrm{VO}_{2 \text { peak }}$, but with no systematic differences between the observed and estimated $\mathrm{VO}_{2 \text { peak }}$. Agreement analyses were not conducted in the original article [12] or in other studies [13, 14]. However, a study of healthy adults [14] has reported a systematic overestimation of 

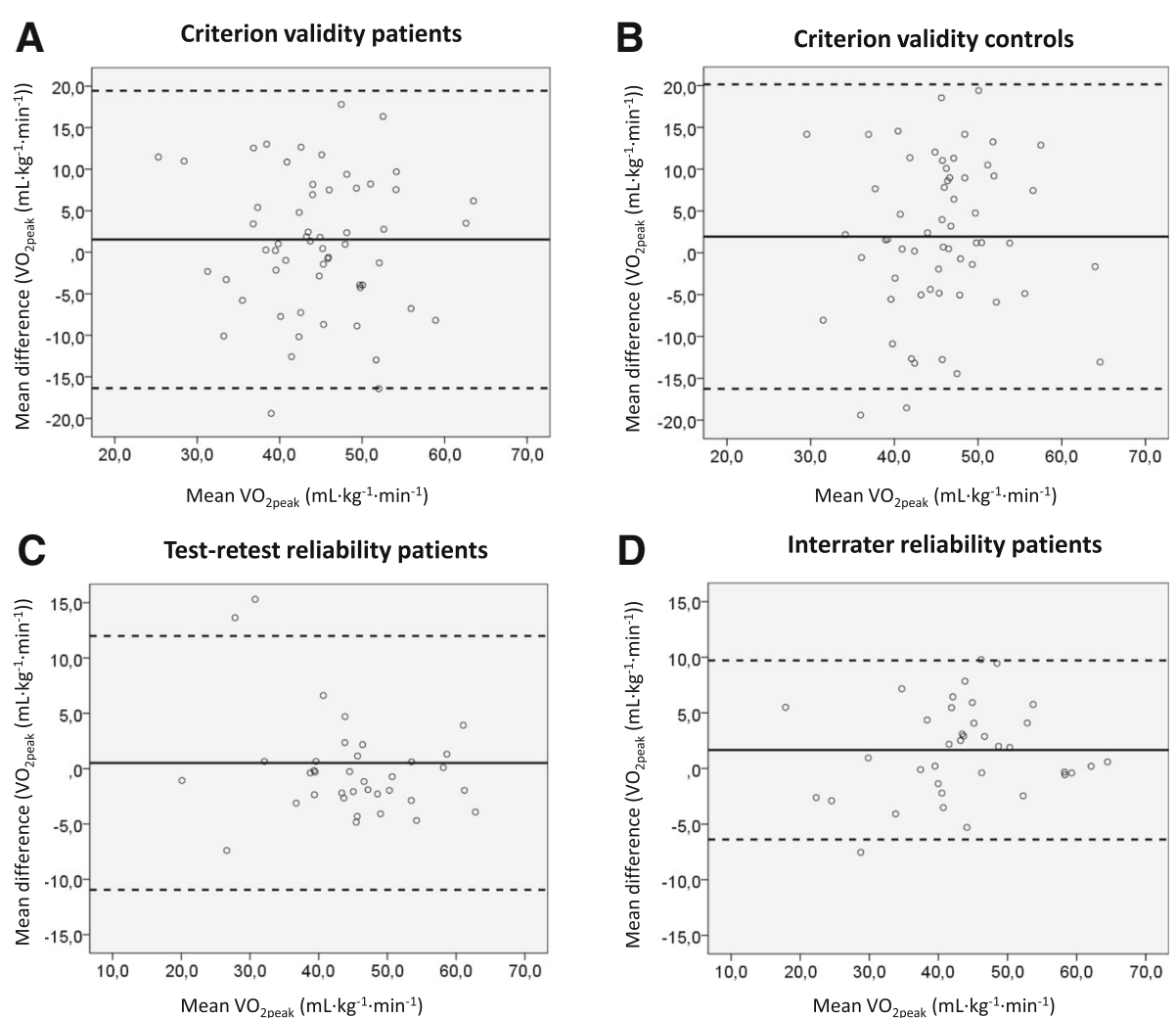

Fig. 2 Bland and Altman plots with the mean scores [(observed+estimated $\left.\mathrm{VO}_{2 \text { peak }}\right) / 2$ ] on the $\mathrm{x}$-axis and mean difference between scores (observed-estimated $\mathrm{VO}_{2 \text { peak }}$ ) on the $\mathrm{y}$-axis for criterion validity in patients with $\mathrm{JIA}(\mathbf{a})$ and controls $(\mathbf{b})$, and the mean scores [(test+retest)/2 and (Tester $1+$ Tester 2)/2] on the $x$-axis and mean difference between scores [(test-retest) and (Tester 1-Tester 2)] on the $y$-axis for test-retest (c) and inter-rater reliability (d) in patients with JIA, respectively. JIA juvenile idiopathic arthritis, $V O_{2 \text { peak }}$ peak oxygen uptake

$\mathrm{VO}_{2 \text { peak }}$ by $3.5 \mathrm{~mL} \cdot \mathrm{kg}^{-1} \cdot \mathrm{min}^{-1}$ when testing at the moderate intensity ( $70 \%$ of the predicted $\left.\mathrm{HR}_{\text {peak }}\right)$ and an underestimation of $\mathrm{VO}_{2 \text { peak }}$ by $3.5 \mathrm{~mL} \cdot \mathrm{kg}^{-1} \cdot \mathrm{min}^{-1}$, when testing at the low intensity ( $50 \%$ of the predicted $\mathrm{HR}_{\text {peak }}$ ). The authors therefore suggested that if the purpose of using the submaximal treadmill test is to evaluate changes in CRF, all test sessions for the individual should be conducted at the same HR rather than the same speed. Thus, we aimed to test the participants at the same HR intensity (close to $70 \%$ of predicted $\mathrm{HR}_{\text {peak }}$ ) when conducting the submaximal tests. With this approach, the SDC was large for both test-retest and inter-rater reliability in our patients.
At group level, a change of more than $1.5 \mathrm{~mL} \cdot \mathrm{kg}^{-1} \cdot \mathrm{min}^{-}$ ${ }^{1}$ and $1.1 \mathrm{~mL} \cdot \mathrm{kg}^{-1} \cdot \mathrm{min}^{-1}$ would be required to be $95 \%$ certain that a real change has occurred for test-retest- and inter-rater testing, respectively. These small $\mathrm{SDC}_{\text {group }}$ values suggest that the submaximal treadmill test is reliable on group level in patients, which is important for research purposes. When mean scores of a group of patients are used instead of individual patient scores, the measurement error becomes smaller and subsequently, the measure is more reliable [17]. If the submaximal treadmill test is used for evaluating change in individual patients in clinical settings, the large measurement errors must be taken

Table 3 Reliability and measurement error of the submaximal treadmill test in patients with JIA

\begin{tabular}{|c|c|c|c|c|c|c|}
\hline & Test* & Retest* & Difference* & SEM agreement & $\mathrm{SDC}_{95}$ & $\mathrm{SDC}_{95 \text { group }}$ \\
\hline \multirow{2}{*}{$\begin{array}{l}\text { Est } \mathrm{VO}_{2 \text { peak }} \\
\left(\mathrm{mL} \cdot \mathrm{kg}^{-1} \cdot \mathrm{min}^{-1}\right)\end{array}$} & $44.9(9.4)$ & $44.3(11.0)$ & $0.5(5.9)$ & 4.1 & 11.4 & 1.5 \\
\hline & Tester $1^{*}$ & Tester $2^{*}$ & Difference* & SEM agreement & $\mathrm{SDC}_{95}$ & $\mathrm{SDC}_{95 \text { group }}$ \\
\hline $\begin{array}{l}\text { Est } \mathrm{VO}_{2 \text { peak }} \\
\left(\mathrm{mL} \cdot \mathrm{kg}^{-1} \cdot \mathrm{min}^{-1}\right)\end{array}$ & $44.3(11.0)$ & $42.7(10.5)$ & $1.6(4.1)$ & 3.1 & 8.6 & 1.1 \\
\hline
\end{tabular}

*Values are mean (SD). JIA juvenile idiopathic arthritis, SEM standard error of measurement, SDC smallest detectable change, Est estimated, $V O_{2 p e a k}$ peak oxygen uptake $N=37$ 
Table 4 Correlation between disease variables and estimated $\mathrm{VO}_{2 \text { peak }}$ and walking distance in patients with JIA

\begin{tabular}{|c|c|c|c|c|}
\hline Disease variable & Estimated $\mathrm{VO}_{2 \text { peak }}$ & $p$-value & Walking distance & $p$-value \\
\hline Use of any medication & -0.07 & 0.59 & -0.10 & 0.47 \\
\hline Use of synthetic DMARDs & 0.04 & 0.79 & -0.04 & 0.76 \\
\hline Use of biologic DMARDs & -0.03 & 0.80 & 0.02 & 0.81 \\
\hline JADAS 71 (0-101) & -0.03 & 0.84 & 0.08 & 0.54 \\
\hline CHAQ (0-3) & -0.13 & 0.35 & -0.18 & 0.17 \\
\hline Active joints & 0.10 & 0.48 & 0.21 & 0.16 \\
\hline Active joints in the lower extremities & 0.09 & 0.46 & 0.20 & 0.13 \\
\hline Disease duration (years) & -0.13 & 0.34 & 0.00 & 0.97 \\
\hline Pain, current (NRS 0-10) & -0.21 & 0.11 & -0.13 & 0.31 \\
\hline Pain, previous week (NRS 0-10) & -0.16 & 0.24 & -0.02 & 0.88 \\
\hline Fatigue, previous week (NRS 0-10) & -0.07 & 0.58 & -0.02 & 0.87 \\
\hline
\end{tabular}

JIA juvenile idiopathic arthritis, DMARDs disease modifying anti-rheumatic drugs, JADAS juvenile arthritis disease activity score, CHAQ childhood health assessment questionnaire, $N R S$ numeric rating scale, $V_{2} O_{2 p a k}$ peak oxygen uptake

into consideration. Specifically, a change of more than $11.4 \mathrm{~mL} \cdot \mathrm{kg}^{-1} \cdot \mathrm{min}^{-1}$ and $8.6 \mathrm{~mL} \cdot \mathrm{kg}^{-1} \cdot \mathrm{min}^{-1}$ are required to be $95 \%$ certain that a real change in a single individual has occurred, for test-retest- and inter-rater testing, respectively.

Submaximal tests are based on the assumption that there is a linear relationship between HR, oxygen consumption, and exercise intensity [8]. Therefore, an accurate age-predicted $\mathrm{HR}_{\text {peak }}$ is of importance. We used the same prediction of $\mathrm{HR}_{\text {peak }}$ as Ebbeling et al. [12] when they developed the test. This equation is proposed to underestimate $\mathrm{HR}_{\text {peak }}$ with increasing age and other equations in adult populations have been suggested $[25,26]$. In our study participants, the mean predicted $\mathrm{HR}_{\text {peak }}$ was 207 in both patients and controls, while the mean $\mathrm{HR}_{\text {peak }}$ observed from the maximal treadmill test was 196 and 197 beat $\cdot \mathrm{min}^{-1}$ in patients and controls, respectively, suggesting overestimation of the predicted $\mathrm{HR}_{\text {peak }}$ when using the 220- age formula. In particular, as $\mathrm{HR}_{\text {peak }}$ varies between individuals, children with low $\mathrm{HR}_{\text {peak }}$ have probably been exercising at higher intensities than $70 \%$. Importantly, there are many factors that may affect HR (e.g. hydration, caffeine, pain and anxiety). Nevertheless, the RPE and HR during the submaximal test indicate that the submaximal treadmill test is a test of submaximal intensity in these participants at group level. The formula by Tanaka et al. (208-0.7 $\mathrm{x}$ age) [25] was better for predicting $\mathrm{HR}_{\text {peak }}$ in both patients and controls than the formula by Nes et al. (211-0.64 $\mathrm{x}$ age) [26] and the 220-age formula [23] (data not shown). The formula by Tanaka et al. was also preferable over the 220-age formula in another study involving children [27].

The estimated $\mathrm{VO}_{2 \text { peak }}$ and the performance of the submaximal treadmill test were comparable between patients with JIA and controls. This is in line with our previous findings studying the same cohort; directly measured
$\mathrm{VO}_{2 \text { peak }}$ was comparable between patients with JIA and controls [7]. Furthermore, we observed no correlation between disease variables and estimated $\mathrm{VO}_{2 \text { peak }}$ and walking distance in patients. We have previously also reported that disease variables were not associated with any components of physical fitness in our patient cohort [7]. Taken together, our results suggest that disease variables are less important for physical fitness, including submaximal performance, in patients treated with a modern multidisciplinary management of JIA.

Our study has several strengths; we applied the COSMIN recommendations for evaluating the criterion validity and reliability of the submaximal treadmill test and the gold standard test was used as criterion measurement. Also, both physiotherapists conducting the submaximal tests for evaluation of reliability were experienced in pediatric rheumatology and one of these physiotherapists also conducted all maximal and submaximal treadmill tests used to evaluate the criterion validity. Also, the sample size was adequate. However, some limitations need to be considered. The equation to estimate the $\mathrm{VO}_{2 \text { peak }}$ was developed in healthy adults aged 20-59 years, and it can be questioned if the formula is valid to use in patients with JIA and controls aged 10-16 years. Our JIA cohort seems well treated with low disease activity and functional disability, thus the findings may not be generalized to patients with higher disease activity or JIA categories not included in the current study. Additionally, the majority of the individuals included in the present study were females, which also could have hampered the generalizability of the results, although the formula used to estimate $\mathrm{VO}_{\text {2peak }}$ takes sex into account. Thus, future research should include other JIA categories and more males to improve the generalizability of the results. 


\section{Conclusions}

In patients with JIA, the submaximal treadmill test shows acceptable criterion validity at group level but not at individual level. The reliability of the test is acceptable, but with large measurement errors for both test-retest- and inter-rater reliability. Our results support that the submaximal treadmill test is valid and reliable for research purposes (on group level), but not optimal to estimate $\mathrm{VO}_{2 \text { peak }}$ in individual patients. Estimated $\mathrm{VO}_{2 \text { peak }}$ and performance of the submaximal treadmill test did not differ between patients and controls and were not associated with disease variables, probably reflecting the positive effect of modern multidisciplinary management of JIA.



6MWT: 6-min walk test; BMl: Body mass index; CHAQ: Childhood health assessment questionnaire; COSMIN: The COnsensus-based Standards for the selection of health Measurement INstruments; CPET: Cardiopulmonary exercise test; CRF: Cardiorespiratory fitness; DMARDs: Disease-modifying antirheumatic drugs; HR: Heart rate; HR peak: Peak heart rate; ICC: Interclass correlation coefficient; ILAR: International League of Associations for Rheumatology; JADAS: Juvenile arthritis disease activity score; JIA: Juvenile idiopathic arthritis; LoA: Limits of agreement; NRS: Numeric rating scale; OUS: Oslo University Hospital; RF: Rheumatoid factor; RPE: Rated perceived exertion; SDC: Smallest detectable change; SEM: Standard error of measurement; $\mathrm{VO}_{2 \text { peak }}$ : Peak oxygen uptake

\section{Acknowledgements}

We are deeply grateful to the children, adolescents and parents participating in this study, and to the staff at the Unit of Paediatric Rheumatology and at the Children's Outpatient Clinic at Rikshospitalet, Oslo University Hospital. Special thanks to the Clinical Research Unit, Department of Pharmacology, Rikshospitalet, Oslo University Hospital, for help with drawing and processing the blood samples from the controls. We are also grateful to Ulrika Nilsson, Section for Orthopaedic Rehabilitation, Division of Orthopaedic Surgery, Oslo University Hospital, for conducting the submaximal treadmill tests used to evaluate the inter-rater reliability of the submaximal treadmill test.

\section{Funding}

This study was funded by The Sophies Minde Foundation.

\section{Availability of data and materials}

The dataset generated and analyzed during the current study is not publicly available due to strict ethical regulation of health related data in Norway. The consent to participate does not include permission to make the data available to a third party.

\section{Authors' contributions}

KR, AMS, HD and HS contributed to the design and conception of the study. KR was responsible for acquisition of data. KR performed the statistical analyses. KR, HD and HS and drafted the manuscript. All authors revised the manuscript critically. All authors read and approved the final manuscript.

\section{Ethics approval and consent to participate}

The study was approved by the Norwegian South East Regional Ethics Committee for Medical Research (2014/188). All participants provided written informed consent (the children themselves if aged $\geq 16$ years and the parents/ guardians of children aged $<16$ years together with the children's assent).

\section{Consent for publication}

Not applicable.

\section{Competing interests}

The authors declare that they have no competing interests.

\section{Publisher's Note}

Springer Nature remains neutral with regard to jurisdictional claims in published maps and institutional affiliations.

\section{Author details}

${ }^{1}$ Division of Orthopaedic Surgery, Section for Orthopaedic Rehabilitation, Oslo University Hospital, Rikshospitalet, Postboks 4950 Nydalen, 0424 Oslo, Norway. ${ }^{2}$ Department of Health Sciences, Institute of Health and Society, Oslo, Faculty of Medicine, University of Oslo, Oslo, Norway. ${ }^{3}$ Department of Pulmonary Medicine, Oslo University Hospital, Ullevål, Oslo, Norway. ${ }^{4}$ Department of Physical Performance, Norwegian School of Sports Sciences, Oslo, Norway. ${ }^{5}$ Department of Rheumatology, Oslo University Hospital, Rikshospitalet, Oslo, Norway. ${ }^{6}$ National Advisory Unit on Rehabilitation in Rheumatology, Diakonhjemmet Hospital, Oslo, Norway. ${ }^{7}$ Norwegian National Advisory Unit on Rheumatic Diseases in Children and Adolescents, Oslo University Hospital, Rikshospitalet, Oslo, Norway. ${ }^{8}$ Bjørknes University College, Oslo, Norway.

Received: 23 January 2019 Accepted: 28 March 2019

Published online: 08 April 2019

\section{References}

1. Lee DC, Artero EG, Sui X, Blair SN. Mortality trends in the general population: the importance of cardiorespiratory fitness. J Psychopharmacol (Oxford, England). 2010;24:27-35.

2. Kaminsky LA, Arena R, Beckie TM, Brubaker PH, Church TS, Forman DE, et al. The importance of cardiorespiratory fitness in the United States: the need for a national registry: a policy statement from the American Heart Association. Circulation. 2013;127:652-62.

3. Melo X, Santa-Clara H, Santos DA, Pimenta NM, Minderico CS, Fernhall B, et al. Linking cardiorespiratory fitness classification criteria to early subclinical atherosclerosis in children. Appl Physiol Nutr Metab. 2015;40:386-92.

4. van Pelt PA, Takken T, van Brussel M, de Witte I, Kruize AA, Wulffraat NM. Aerobic capacity and disease activity in children, adolescents and young adults with juvenile idiopathic arthritis (JIA). Pediatr Rheumatol Online J. 2012;10:27.

5. Hassan J, van der Net J, Helders PJ, Prakken BJ, Takken T. Six-minute walk test in children with chronic conditions. Br J Sports Med. 2010;44:270-4.

6. Lelieveld OT, Takken T, van der Net J, van Weert E. Validity of the 6-minute walking test in juvenile idiopathic arthritis. Arthritis Rheum. 2005;53:304-7.

7. Risum K, Edvardsen E, Godang K, Selvaag AM, Hansen BH, Molberg O, et al. Physical fitness in patients with oligo- and Polyarticular juvenile idiopathic arthritis diagnosed in the era of biologics - a controlled cross-sectional study. Arthritis Care Res (Hoboken). 2018. https://doi.org/10.1002/acr.23818.

8. Bar-Or O, Rowland T. Pediatric Exercise Medicine: From Physiologic Principles to Health Care Application. Champaign: Human Kinetics; 2004

9. American College of Sports Medicine. ACSM's guidelines for exercise testing and prescription. Philadelphia: Wolters Kluwer; 2017.

10. Bartels B, de Groot JF, Terwee CB. The six-minute walk test in chronic pediatric conditions: a systematic review of measurement properties. Phys Ther. 2013;93:529-41.

11. Paap E, van der Net J, Helders PJ, Takken T. Physiologic response of the sixminute walk test in children with juvenile idiopathic arthritis. Arthritis Rheum. 2005;53:351-6.

12. Ebbeling CB, Ward A, Puleo EM, Widrick J, Rippe JM. Development of a single-stage submaximal treadmill walking test. Med Sci Sports Exerc. 1991; 23:966-73.

13. Minor MA, Johnson JC. Reliability and validity of a submaximal treadmill test to estimate aerobic capacity in women with rheumatic disease. J Rheumatol. 1996;23:1517-23.

14. Waddoups L, Wagner D, Fallon J, Heath E. Validation of a single-stage submaximal treadmill walking test. J Sports Sci. 2008;26:491-7.

15. Risum K, Hansen BH, Selvaag AM, Molberg O, Dagfinrud H, Sanner H. Physical activity in patients with oligo- and polyarticular juvenile idiopathic arthritis diagnosed in the era of biologics: a controlled cross-sectional study. Pediatr Rheumatol Online J. 2018;16:64.

16. Petty RE, Southwood TR, Manners P, Baum J, Glass DN, Goldenberg J, et al. International league of associations for rheumatology classification of juvenile idiopathic arthritis: second revision, Edmonton, 2001. J Rheumatol. 2004;31:390-2. 
17. de Vet $H$, Terwee CB, Mokkink LB, Knol DL. Measurement in Medicine. United Kingdom: Cambridge University Press; 2011.

18. Weiss JE, Luca NJ, Boneparth A, Stinson J. Assessment and management of pain in juvenile idiopathic arthritis. Paediatr Drugs. 2014;16:473-81.

19. Consolaro A, Ruperto N, Bazso A, Pistorio A, Magni-Manzoni S, Filocamo G, et al. Development and validation of a composite disease activity score for juvenile idiopathic arthritis. Arthritis Rheum. 2009;61:658-66.

20. Wallace CA, Giannini EH, Huang B, Itert L, Ruperto N. American College of Rheumatology provisional criteria for defining clinical inactive disease in select categories of juvenile idiopathic arthritis. Arthritis Care Res (Hoboken). 2011:63:929-36.

21. Singh $G$, Athreya BH, Fries JF, Goldsmith DP. Measurement of health status in children with juvenile rheumatoid arthritis. Arthritis Rheum. 1994;37:1761-9.

22. Flato B, Sorskaar D, Vinje O, Lien G, Aasland A, Moum T, et al. Measuring disability in early juvenile rheumatoid arthritis: evaluation of a Norwegian version of the childhood health assessment questionnaire. J Rheumatol. 1998:25:1851-8.

23. Fox SM 3rd, Naughton JP, Haskell WL. Physical activity and the prevention of coronary heart disease. Ann Clin Res. 1971;3:404-32.

24. Borg GA. Perceived exertion. Exerc Sport Sci Rev. 1974;2:131-53.

25. Tanaka H, Monahan KD, Seals DR. Age-predicted maximal heart rate revisited. J Am Coll Cardiol. 2001:37:153-6.

26. Nes BM, Janszky I, Wisloff U, Stoylen A, Karlsen T. Age-predicted maximal heart rate in healthy subjects: the HUNT fitness study. Scand J Med Sci Sports. 2013;23:697-704.

27. Mahon AD, Marjerrison AD, Lee JD, Woodruff ME, Hanna LE. Evaluating the prediction of maximal heart rate in children and adolescents. Res Q Exerc Sport. 2010;81:466-71.

Ready to submit your research? Choose BMC and benefit from:

- fast, convenient online submission

- thorough peer review by experienced researchers in your field

- rapid publication on acceptance

- support for research data, including large and complex data types

- gold Open Access which fosters wider collaboration and increased citations

- maximum visibility for your research: over $100 \mathrm{M}$ website views per year

At $\mathrm{BMC}$, research is always in progress.

Learn more biomedcentral.com/submissions 